\title{
Factors Associated With The Prevalence And Severity of Nausea While Undergoing Radiation Among Women Diagnosed With Early-Stage Breast Cancer
}

Caroline Harpel ( $\nabla$ ckh7@pitt.edu )

University of Pittsburgh School of Nursing https://orcid.org/0000-0002-8801-9341

\section{Susan M. Sereika}

University of Pittsburgh School of Nursing

Karen Alsbrook

University of Pittsburgh School of Nursing

\section{Susan Grayson}

University of Pittsburgh School of Nursing

\section{Susan Wesmiller}

University of Pittsburgh School of Nursing

\section{Research Article}

Keywords: Breast cancer, Radiotherapy, Nausea, Risk Factors

Posted Date: June 9th, 2021

DOI: https://doi.org/10.21203/rs.3.rs-481513/v1

License: (a) (i) This work is licensed under a Creative Commons Attribution 4.0 International License. Read Full License 


\section{Abstract}

Purpose. The purpose of this study was to estimate radiation-induced nausea (RIN) prevalence and severity among 183 women with early-stage breast cancer and to identify its predictors.

Methods. Among participants who underwent radiotherapy, a case-control design compared those who experienced RIN to those who did not. Nausea was measured weekly and operationalized on an 11-point scale with ' 0 ' representing "no nausea" and ' 10 ' representing the "worst nausea ever experienced." Participants selfreported these symptoms while undergoing radiotherapy. Predictor variables were identified using multivariable binary logistic regression for RIN prevalence and multiple linear regression for RIN severity.

Results. Over forty percent $(n=75)$ of participants undergoing radiotherapy experienced RIN, with a mean nausea severity rating of $3.27 / 10$. Significant predictors of RIN prevalence were higher pain levels $(p<0.0001)$, history of motion sickness $(p=0.024)$, and younger age $(p=0.032)$. Higher pain levels $(p<0.0001)$, younger age $(p=0.038)$ and history of postoperative nausea $(p=0.042)$ were significant predictors of increased RIN severity.

Conclusions. The RIN prevalence of 41.0 percent among study participants was higher than previously reported for patients undergoing breast radiotherapy. This could be due to the collection of weekly selfreported data that quantified RIN severity. Younger age, history of nausea, and higher average pain levels should be identified as potential RIN risk factors among patients with early-stage breast cancer. Risk factor identification at the onset of radiotherapy would allow for increased prophylactic mitigation of RIN.

\section{Background}

Radiation-induced nausea (RIN) is a common side effect experienced by patients with cancer undergoing radiotherapy, with an overall prevalence between 50 and 80 percent (1). Patients with RIN report decreased well-being, quality of life, and satisfaction with aspects of daily living, regardless of the severity of their nausea (2).

The presence and severity of RIN depend on the location and size of the of the radiation field as well as the dose and number of fractions of radiation the patient receives (1). As such, RIN is classified into four risk groupings: high, moderate, low, and minimal (3). The high-risk grouping is comprised of patients undergoing total body irradiation and total nodal irradiation. The moderate-risk group includes those receiving upper abdominal irradiation, hemibody irradiation, and upper body irradiation. Patients undergoing cranial, craniospinal, head and neck, lower thorax region, or pelvic irradiation comprise the low-risk group (4). Lastly, the minimal risk group is comprised of patients receiving irradiation of the extremities or breast irradiation, where generally less than 30 percent of patients undergoing radiation experience RIN (1).

For higher-risk groups, RIN is treated prophylactically, typically through the administration of serotonin receptor antagonists (1). However, antiemetic guidelines are unclear and often contradictory, and no such guidelines exist for administration of antiemetics to those in the minimal-risk grouping (5).

A multifactorial analysis of 914 patients enrolled in a study by the Italian Group for Antiemetic Research in Radiotherapy revealed that the only significant patient-related risk factor for RIN was neoadjuvant 
chemotherapy (4). Other, smaller-scale studies have reported correlations between RIN and the following symptoms: being age 40 years or younger; previous history of nausea; female gender; anxiety (2); " $A$ " blood type (6), and radiation breast side (7). In healthy adults aged 20-25 years, left-handedness was also shown to be significantly associated with radiosensitivity (8).

Previous studies on RIN were conducted among moderate and high-risk groups. However, these findings are not generalizable to minimal-risk groups, which may be prescribed different antiemetic protocols (5). Risk factors other than radiation-related variables have not been extensively researched in minimal risk groupings (9). In a systematic review of the RIN literature, Dennis et al. (2017) reported that none of the studies that aimed to measure nausea provided a definition for the term. Further, nausea was always measured as a stand-alone symptom (yes/no) or in terms of severity graded with categorical qualitative scales (e.g., "none," "mild," "moderate," or "severe") (9).

In a response to the gap not filled by previous studies, our study conceptualized nausea as "the feeling that you could vomit" through use of the Patient-Reported Outcomes Measurement Information System Gastrointestinal Nausea and Vomiting Scale (PROMISGI®) (10). We operationalized nausea on an 11-point numerical rating scale with ' 0 ' representing "no nausea" and ' 10 ' representing the "worst nausea ever experienced."

The purpose of this study was twofold: 1 ) to estimate prevalence and severity of RIN;2) to explore possible factors that could be associated with the prevalence and severity of nausea during radiation in women diagnosed with early-stage breast cancer participating in an ongoing prospective cohort study. Based on previous research, it is hypothesized that women who are less than 40 years old, have a positive history of nausea, have a history of neoadjuvant chemotherapy, underwent either a total mastectomy or breast cancer surgery on the left side, and who are left-handed are at greater risk for RIN in both prevalence and severity.

\section{Methods}

\section{Design}

This study employed a case-control design using data collected from a larger, ongoing prospective study (NIH R01-NR0196556) with repeated assessments characterizing the phenotypes and genotypes of treatment induced nausea and vomiting in women with early-stage breast cancer for one year following surgery for breast cancer ( $n=287)$. A "case" was defined as a study participant who reported a numerical rating scale nausea score greater than zero at least once while undergoing radiotherapy for breast cancer. In contrast, a "control" was defined as a study participant who did not report any nausea while undergoing radiotherapy for breast cancer. Use of a case-control design is appropriate, as this study aimed to identify certain pre-existing risk factors that could predict the presence and severity of RIN (11).

\section{Setting}

Rigorously trained members of the research team recruited and consented study participants and collected baseline data in the preoperative holding area of a large academic hospital specializing in care of women. The academic hospital houses a nationally known comprehensive Breast Care Program. 


\section{Sample}

Inclusion criteria for the parent study required diagnosis of an early-stage breast cancer, classified as Stage I, II or Illa per the American Joint Committee on Cancer staging criteria (12) and scheduled to undergo breast surgery lasting four hours or less. Exclusion criteria included a previous history of neurologic conditions such as stroke, head injury, spinal cord injury, intracerebral hemorrhage, and surgical procedures anticipated to last greater than four hours. For this secondary analysis, only data from study participants who underwent radiotherapy between May 24, 2018 and March 1, $2021(n=183)$ were included.

\section{Measurement}

\section{Baseline Data}

Baseline data collected from study participants in the preoperative holding area included: (1) smoking history, (2) history of nausea during pregnancy, (3) history of motion sickness, (4) family history of nausea and vomiting, (5) race, (6) history of postoperative nausea and vomiting, (7) type of surgery, (8) handedness and (9) surgical side.

\section{Medical Chart Data}

Neoadjuvant therapy, estrogen receptor and progesterone receptor data were abstracted from study participants' medical charts due to their potential relationships with treatment induced nausea and vomiting.

\section{Weekly Survey Data}

Upon discharge from the hospital following surgery for breast cancer, study participants were called or emailed on a weekly basis to complete a survey administered by trained study team members. Information collected from the survey consisted of self-report of current breast cancer treatment and pain reported using the numerical rating scale, and questions from the PROMIS-29Ò. Study participants self-reported nausea using the numerical rating scale and the nausea and vomiting subscale from the PROMISGIÒ. In addition, types and dosages of prescribed and over-the-counter medications and alternative therapies used to alleviate pain and nausea were collected. All study participants who identified "radiation" as their current treatment were included in this analysis. Study participants undergoing another breast cancer treatment in conjunction with radiation (e.g., taking an aromatase inhibitor, receiving Herceptin or Perjeta infusions) were also included in this sample.

Weekly symptom assessments were completed over the entire period that study participants underwent radiotherapy. Pain and nausea were assessed on the 11-point numerical rating scale, with 0 representing no pain or no nausea and a score of 10 representing the worst imaginable pain or nausea ever experienced. Average pain and nausea scores for each individual were calculated by summing each collected score and dividing by the number of queries from weekly phone and email surveys.

\section{Statistical Analysis}


The data analysis was performed using the SAS software, Version 9.4 for Windows (SAS Institute Inc., Cary, NC, USA). A p-value less than 0.05 indicated statistical significance for non-directional hypothesis testing. Confidence interval estimation was at 95 percent. Exploratory analysis consisted of assessing baseline characteristics for cases and controls and possible multicollinearity.

Descriptive analyses were used to obtain means and standard deviations for continuous type variables, and to obtain frequencies and percentages for categorical variables. There were two participants who reported much higher nausea severity and pain scores than did the other participants experiencing RIN. Upon comparing the means and medians of these variables, it was found that the outliers did not skew the data for either variable. Baseline categorical characteristics of study participants who reported RIN and those who did not report any RIN were compared using chi-squared tests for independence or Fisher's exact tests. Continuous variables were checked for normality. Since none of the continuous variables were normally distributed, Wilcoxon sum-rank tests were used to obtain these baseline characteristics.

Binary logistic and linear regression analyses were performed to identify factors that could be associated with (a) RIN prevalence and (b) RIN severity. The dependent variable for the binary logistic regression was the presence of RIN, while the dependent variable for the linear regression was the severity of RIN. To explore possible non-additivity, two-way interactions between all predictor variables were assessed and included as their own variables in the predictive modeling approach. Forward selection was used to fit the best model. A Box-Tidwell approach was implemented to assess the linearity in the logit assumption for continuous-type predictors. Thus, interaction terms of the continuous type predictor variable and its natural logarithm were added to the binary logistic regression models as well. If the added interactions were statistically significant, this was a violation of linearity in the logit assumption and each continuous predictor in question was transformed to "linearize" the nonlinearity in the observed logit. Pain and age variables were centered by subtracting the mean pain score and age, respectively from the values for each variable. These centered variables were used in subsequent analyses. Categorical predictor variables with k levels were converted to k1 dummy variables for regression analysis, with one level in each categorical predictor variable serving as the reference category.

\section{Results}

Among women diagnosed with early-stage breast cancer enrolled in the Treatment-Induced Nausea and Vomiting study $(\mathrm{N}=287)$ at the University of Pittsburgh (NR0196556), 63.8 percent underwent adjuvant radiotherapy $(n=183)$, and the prevalence of RIN was 41.0 percent $(n=75)$.

\section{Baseline Characteristics: Cases versus Controls}

The baseline characteristics of the 183 women included in the current analysis are summarized in Table 1. Compared to controls who reported no RIN, cases reported higher average pain levels $(p<0.0001)$. The mean pain score among participants who experienced RIN was nearly twice that of participants who did not experience RIN. Cases reported a mean pain score of 3.92/10, while controls reported a mean pain level of 1.89/10. Less than one third of controls reported use of over-the-counter medications to manage pain, and only three reported using prescription medication to manage it. In contrast, nearly two-thirds of cases reported 
use of pain medication at least once, with 36 using over-the-counter medications and 11 using prescription medications. Overall, cases were significantly younger $(p=0.024)$, with a mean age of 58.87 years (median: $59.0)$ compared to controls, who had a mean age of 62.82 years (median: 65.0 ). Cases reported significantly higher rates of history of nausea, including family history of nausea and vomiting $(p=0.052)$, history of motion sickness $(p=0.051)$, and history of postoperative nausea and vomiting $(p=0.048)$.

Cases and controls did not significantly differ in estrogen receptor positivity, history of nausea during pregnancy, progesterone receptor positivity, surgical side, smoking history, surgery type, history of neoadjuvant therapy, handedness, or race.

\section{Nausea Findings}

Among cases, mean nausea severity was $3.27 / 10$, with a median score of 3.00 , and mean scores ranging from 0.25 to 10 .

Table 1: Participant Characteristics by Radiation Induced Nausea (RIN) Status ( $N=183$ ) 


\begin{tabular}{|c|c|c|c|c|}
\hline Characteristic & $\begin{array}{l}\text { No } \operatorname{RIN}(\mathrm{n}=108) \\
\mathrm{n}(\%)\end{array}$ & $\begin{array}{l}\mathrm{RIN}(\mathrm{n}=75) \\
\mathrm{n}(\%)\end{array}$ & $\begin{array}{l}\text { Odds Ratio } \\
\text { (95\% Confidence } \\
\text { Interval) }\end{array}$ & $\begin{array}{l}\mathrm{p}- \\
\text { value }\end{array}$ \\
\hline \multirow[t]{2}{*}{ Concurrent Treatment } & No: 90 (83.3\%) & No: 55 (73.3\%) & 1.82 & \multirow[t]{2}{*}{0.101} \\
\hline & Yes: 18 (16.7\%) & Yes: 20 (26.7\%) & $(0.89,3.73)$ & \\
\hline \multirow[t]{2}{*}{ Estrogen Receptor } & $\begin{array}{l}\text { Negative: } 26 \\
(25.0 \%)\end{array}$ & $\begin{array}{l}\text { Negative: } 16 \\
(21.9 \%)\end{array}$ & \multirow{2}{*}{$\begin{array}{l}1.19 \\
(0.58,2.42)\end{array}$} & \multirow[t]{2}{*}{0.635} \\
\hline & $\begin{array}{l}\text { Positive: } 78 \\
\text { (75.0\%) }\end{array}$ & $\begin{array}{l}\text { Positive: } 57 \\
\text { (78.1\%) }\end{array}$ & & \\
\hline \multirow{2}{*}{$\begin{array}{l}\text { Family History of Nausea and } \\
\text { Vomiting }\end{array}$} & No: 87 (80.6\%) & No: 51 (68.0\%) & 1.95 & \multirow[t]{2}{*}{0.052} \\
\hline & Yes: 21 (19.4\%) & Yes: 24 (32.0\%) & $(0.99,3.85)$ & \\
\hline \multirow[t]{2}{*}{ Motion Sickness } & No: 73 (67.6\%) & No: 40 (53.3\%) & 1.83 & \multirow[t]{2}{*}{0.051} \\
\hline & Yes: 35 (32.4\%) & Yes: 35 (46.7\%) & $(0.99,3.35)$ & \\
\hline \multirow[t]{2}{*}{ Prescription Opioids[1] } & No: 105 (97.2\%) & No: 64 (85.3\%) & 8.86 & \multirow[t]{2}{*}{0.004} \\
\hline & Yes: 3 (2.8\%) & Yes: $11(14.7 \%)$ & $(1.62,22.38)$ & \\
\hline \multirow[t]{2}{*}{ Pregnancy Nausea } & No: 73 (67.6\%) & No: $41(54.7 \%)$ & 1.73 & \multirow[t]{2}{*}{$0.07 €$} \\
\hline & Yes: 35 (32.4\%) & Yes: 34 (45.3\%) & $(0.94,3.18)$ & \\
\hline \multirow[t]{2}{*}{ Postoperative Nausea } & No: 86 (79.6\%) & No: 50 (66.7\%) & 1.95 & \multirow[t]{2}{*}{$0.04 \varepsilon$} \\
\hline & Yes: 22 (20.4\%) & Yes: 25 (33.3\%) & $(1.01,3.82)$ & \\
\hline \multirow[t]{2}{*}{ Progesterone Receptor } & $\begin{array}{l}\text { Negative: } 27 \\
\text { (26.5\%) }\end{array}$ & $\begin{array}{l}\text { Negative: } 21 \\
\text { (28.8\%) }\end{array}$ & \multirow{2}{*}{$\begin{array}{l}0.89 \\
(0.46,1.74)\end{array}$} & \multirow[t]{2}{*}{0.737} \\
\hline & $\begin{array}{l}\text { Positive: } 75 \\
\text { (73.5\%) }\end{array}$ & $\begin{array}{l}\text { Positive: } 52 \\
\text { (71.2\%) }\end{array}$ & & \\
\hline \multirow[t]{3}{*}{ Surgical Side* } & Left: 51 (47.2\%) & Left: $37(49.3 \%)$ & 1.09 & \multirow[t]{3}{*}{0.942} \\
\hline & $\begin{array}{l}\text { Bilateral: } 13 \\
(12.0 \%)\end{array}$ & $\begin{array}{l}\text { Bilateral: } 8 \\
(10.7 \%)\end{array}$ & $(0.60,1.96)$ & \\
\hline & Right: 44 (40.8\%) & Right: 30 (40.0\%) & & \\
\hline \multirow[t]{2}{*}{ Smoking History } & $\begin{array}{l}\text { Nonsmoker: } 102 \\
(94.4 \%)\end{array}$ & $\begin{array}{l}\text { Nonsmoker: } 68 \\
(90.7 \%)\end{array}$ & \multirow{2}{*}{$\begin{array}{l}1.75 \\
(0.56,5.43)\end{array}$} & \multirow[t]{2}{*}{0.328} \\
\hline & Smoker: 6 (5.6\%) & Smoker: 7 (9.3\%) & & \\
\hline \multirow[t]{2}{*}{ Mastectomy Type } & $\begin{array}{l}\text { Segmental: } 88 \\
(81.5 \%)\end{array}$ & $\begin{array}{l}\text { Segmental: } 58 \\
(77.3 \%)\end{array}$ & \multirow{2}{*}{$\begin{array}{l}1.29 \\
(0.62,2.67)\end{array}$} & \multirow[t]{2}{*}{0.492} \\
\hline & Total: 20 (18.5\%) & Total: $17(22.7 \%)$ & & \\
\hline \multirow[t]{2}{*}{ Neoadjuvant Therapy } & No: 82 (75.9\%) & No: 56 (74.7\%) & 1.11 & \multirow[t]{2}{*}{0.760} \\
\hline & Yes: 25 (24.1\%) & Yes: 19 (25.3\%) & $(0.56,2.21)$ & \\
\hline
\end{tabular}




\begin{tabular}{|c|c|c|c|c|}
\hline \multirow[t]{2}{*}{ Handedness } & Right: 86 (79.6\%) & Right: 61 (81.3\%) & 0.60 & 0.325 \\
\hline & Left: 14 (20.4\%) & Left: 6 (18.7\%) & $(0.22,1.66)$ & \\
\hline \multirow[t]{3}{*}{ Race } & White: 94 (87.0\%) & White: 67 (89.3\%) & 0.80 & 0.639 \\
\hline & $\begin{array}{l}\text { Nonwhite: } 14 \\
\text { (13.0\%) }\end{array}$ & $\begin{array}{l}\text { Nonwhite: } 8 \\
(10.7 \%)\end{array}$ & $(0.32,2.02)$ & \\
\hline & $\begin{array}{l}\text { Mean (SD) - } \\
\text { Controls }\end{array}$ & $\begin{array}{l}\text { Mean (SD) - } \\
\text { Cases }\end{array}$ & & \\
\hline Average Pain Level & $1.89(2.05)$ & $3.92(2.83)$ & 1.390 & $<0.001$ \\
\hline (0-10 scale) & & & $(1.211,1.596)$ & \\
\hline \multirow[t]{2}{*}{ Age (years) } & $62.82(11.74)$ & $58.87(10.78)$ & 0.970 & 0.024 \\
\hline & & & $(0.945,0.996)$ & \\
\hline
\end{tabular}

*Left breast surgery used as referent category for odds ratio calculation.

Note: "Yes," "Positive," "Smoker," and "Left" were used as the present variables in odds ratio calculations

\section{[1] Fisher's Exact test used}

Table 2: Association of Risk Factors with the Probability of Having RIN - Logistic Regression

\begin{tabular}{|c|c|c|c|c|c|c|}
\hline \multirow[t]{2}{*}{ Variables } & \multirow[t]{2}{*}{$\begin{array}{l}\text { Crude Odds } \\
\text { Ratio }\end{array}$} & \multirow[t]{2}{*}{$\begin{array}{l}\text { Wald Chi-squared } \\
\text { p-value }\end{array}$} & \multirow[t]{2}{*}{$\begin{array}{l}\text { Adjusted } \\
\text { Odds Ratio }\end{array}$} & \multirow{2}{*}{$\begin{array}{l}\text { Wald Chi- } \\
\text { squared } \\
\text { p-value }\end{array}$} & \multicolumn{2}{|c|}{$\begin{array}{l}95 \% \text { Confidence } \\
\text { Interval }\end{array}$} \\
\hline & & & & & Lower & Upper \\
\hline Pain & 1.390 & $<0.0001$ & 1.536 & $<0.0001$ & 1.268 & 1.862 \\
\hline $\begin{array}{l}\text { Motion } \\
\text { Sickness }{ }^{1}\end{array}$ & 1.825 & 0.052 & 2.280 & 0.024 & 1.112 & 4.673 \\
\hline Age (years) & 0.970 & 0.024 & 0.965 & 0.032 & 0.933 & 0.997 \\
\hline $\begin{array}{l}\text { Postoperative } \\
\text { Nausea }^{2}\end{array}$ & 1.955 & 0.050 & 1.847 & 0.116 & 0.860 & 3.965 \\
\hline $\begin{array}{l}\text { Prescription } \\
\text { Opioids }^{3}\end{array}$ & 8.857 & 0.004 & 1.339 & 0.065 & 0.918 & 15.854 \\
\hline
\end{tabular}

${ }^{1}$ Reference category for history of motion sickness is "No history of motion sickness."

${ }^{2}$ Reference category for history of postoperative nausea is "No history of postoperative nausea."

${ }^{3}$ Reference category for prescription opioids is "No prescription opioids."

\section{Binary Logistic Regression for RIN}


Table 2 summarizes the results of the multivariable binary logistic regression analysis of RIN prevalence predictors. In this model, average pain level, age and having a history of motion sickness were significant predictors of RIN. Adjusting for all other variables in the model, an increase in pain by one unit of measure increased the odds ratio of RIN by $1.54(\mathrm{OR}=1.536,95 \% \mathrm{Cl}=1.268-1.862, \mathrm{p}<0.0001)$. In this model, history of motion sickness doubled the odds of $\mathrm{RIN}(\mathrm{OR}=2.280,95 \% \mathrm{Cl}=1.112-4.673, \mathrm{p}=0.024)$. An increase in age by one year resulted in 0.03 lower odds of reporting $\mathrm{RIN}(\mathrm{OR}=0.970,95 \% \mathrm{Cl}=0.933-0.997, \mathrm{p}=0.032)$. There was a positive relationship between prescription opioid use and RIN prevalence, but this relationship was not significant $(p=0.065)$.

\section{Linear Regression for RIN Severity}

Table 3 reports the results from the multiple linear regression analysis where average nausea severity was the dependent variable. The full multiple linear regression model yielded an adjusted $\mathrm{R}^{2}$ of 0.198 . Thus, 19.8 percent of variation in RIN severity can be explained by the predictors in this model. Average pain level and history of postoperative nausea were significantly associated with increased RIN severity. For every one-point increase in average pain level, average RIN severity increased by nearly one-half of a point $(p<0.0001)$. If history of postoperative nausea and vomiting was reported, average RIN severity increased by 0.138 points ( $p$ $=0.042$ ). Older age was significantly associated with decreased RIN severity. For every one-year increase in age, average RIN severity decreased by 0.144 points $(p=0.038)$.

Table 3: Association of Risk Factors with Average Radiation Induced Nausea Severity - Linear Regression

\begin{tabular}{|llllllll|}
\hline Variable & $\begin{array}{l}\text { Unstandardized } \\
\text { Regression } \\
\text { Coefficient, } \boldsymbol{b}\end{array}$ & $\begin{array}{l}\text { Standard } \\
\text { Error for } \\
\boldsymbol{b}\end{array}$ & $\begin{array}{l}\boldsymbol{t} \text { - } \\
\text { value }\end{array}$ & $\begin{array}{l}\boldsymbol{p} \text { - } \\
\text { value }\end{array}$ & $\begin{array}{l}\text { Standardized } \\
\text { Regression } \\
\text { Coefficient }\end{array}$ & $\begin{array}{l}\text { 95\% } \\
\text { Confidence } \\
\text { Interval Limits } \\
\text { for } \boldsymbol{b}\end{array}$ \\
\hline Pain & 0.344 & 0.057 & 6.045 & $<0.001$ & 0.413 & 0.232 & 0.456 \\
\hline Age & -0.026 & 0.012 & -2.088 & 0.038 & -0.144 & -0.050 & -0.001 \\
\hline $\begin{array}{l}\text { Postoperative } \\
\text { Nausea }\end{array}$ & 0.655 & 0.320 & 2.045 & 0.042 & 0.138 & 0.023 & 1.286 \\
\hline $\begin{array}{l}\text { Neoadjuvant } \\
\text { Chemotherapy }\end{array}$ & -0.614 & 0.343 & -1.790 & 0.075 & -0.127 & -1.291 & 0.063 \\
\hline
\end{tabular}

\section{Discussion}

The RIN prevalence of $41 \%$ among study participants was higher than the typically expected rate for patients with breast cancer undergoing radiotherapy (1). This could be due to factors such as the co-occurrence of pain. Alternatively, it could be due to the collection of weekly self-reported data that quantified RIN on a 0-10 scale as opposed to as a stand-alone symptom or on categorical qualitative scales. Opioid use is a known risk factor for treatment-induced nausea $(13 ; 14)$, yet was not a statistically significant predictor of RIN prevalence or severity after adjusting for other factors. Even when all study participants who had taken at least one dose of opioids for pain $(n=14)$ were excluded from analysis, RIN prevalence remained over 34 percent. 
According to the RIN literature, age less than 40 years (2), history of nausea (2), neoadjuvant chemotherapy (3), and history of left-sided breast surgery (7) have been identified as risk factors for more severe RIN. Our analysis supported the existing literature that younger age, history of motion sickness, and prescription opioid use are associated with RIN prevalence. We also found that younger age and history of postoperative nausea are associated with RIN severity, as is history of neoadjuvant chemotherapy. Further, our analysis concluded that average pain level was strongly associated with both RIN prevalence and severity, even when participants taking prescription opioids were excluded from analysis.

Participants of color were underrepresented in this study, with only two Asian and 20 black participants, who were grouped together in the "nonwhite" category to retain statistical power. The literature suggests that black and Asian women tend to experience different symptom burdens, with black women reporting lower rates of nausea and vomiting compared to white women (15), and Asian women reporting higher rates (16). These differences can be further explored in future studies through oversampling of these populations. In addition, the underrepresentation of black participants can be partially attributed to the higher prevalence of triplenegative breast cancer, an aggressive subtype, within this demographic (17). Adjuvant radiation therapy is not an effective treatment for women with early-stage, triple-negative breast cancer (18), for whom adjuvant chemotherapy is the standard of care (19).

Strengths of this study included the conceptualization of RIN on a numerical rating scale, the recurring collection of self-reported participant data on a weekly basis, and the simultaneous measurement of RIN and pain level. Review of the literature did not reveal that RIN and pain level had been measured simultaneously in prior studies. This study could inform future research and clinical practice by suggesting pain management as a means of mitigating RIN.

This analysis supports that younger age, history of motion sickness, and higher average pain levels should be identified as potential risk factors for RIN among patients with early-stage breast cancer who are undergoing radiotherapy. The identification of these risk factors at the onset of radiotherapy would allow for increased prophylactic mitigation of RIN.

\section{Declarations}

\section{Funding}

This study was funded by the National Institute of Nursing Research Grant NR0196556.

\section{Conflicts of Interest}

The authors have no relevant financial or non-financial interests to disclose.

\section{Availability of Data and Material}

All primary data are housed at the University of Pittsburgh School of Nursing and are available on request. The data file used for analysis is included with this manuscript submission.

\section{Code Availability}

Page 10/12 
The data analysis was performed using the SAS software, Version 9.4 for Windows (SAS Institute Inc., Cary, NC, USA). The code is saved as a SAS file and is available upon request.

\section{Authors' Contributions}

$\mathrm{CH}$ was responsible for study conception and design. $\mathrm{CH}, \mathrm{KA}$, and SG were responsible for data collection. SMS and $\mathrm{CH}$ were responsible for data preparation, data analysis and interpretation of results. SW was the principal investigator for the parent study. All authors reviewed the results and approved the final version of this manuscript.

\section{Ethics Approval}

This research study and its protocols have been approved by the University of Pittsburgh Institutional Review Board. IRB: CR19030259-014

\section{Consent to Participate}

Not applicable.

\section{Consent for Publication}

Not applicable.

\section{References}

1. An Overview of Radiation-Induced Nausea and Vomiting. Rowbottom, L, et al. 2016, Journal of medical imaging and radiation sciences, pp. S29-S38.

2. One third of patients with radiotherapy-induced nausea consider their antiemetic treatment insufficient. Enblom, A, et al. Linkoping : Supportive Care in Cancer, 2009, Vol. 17. 10.1007s00520-008-445.

3. Evidence-based recommendations for the use of antiemetics in radiotherapy. Maranzano, E, et al. 2005, Radiotherapy and oncology: journal of the European Society for Therapeutic Radiology and Oncology, pp. 227-233.

4. Prophylactic Management of Radiation-Induced Nausea and Vomiting. Feyer, P, Jahn, F and Jordan, K. 2015, BioMed research international.

5. Radiation-induced nausea and vomiting: a comparison between MASCC/ESMO, ASCO, and NCCN antiemetic guidelines. McKenzie, E, et al. 2019, Supportive Care in Cancer, pp. 783-791.

6. Radiation-induced nausea and vomiting: Is ABO blood group as important as radiation and patientrelated factors? An observational study. Habibi, M, Namimoghadam, A and Kourouni, R. 2016, Medicine (Baltimore), p. e4334.

7. VMAT radiation induced nausea and vomiting in adjuvant breast cancer radiotherapy: The incidental effect of low-dose bath exposure. Lazzari, G, et al. 2017, Clinical and Translational Radiation Oncology, pp. 43-48. 
8. The study of radiosensitivity in left handed compared to right handed healthy women. Khosravifarsani, M, et al. 2012, BMC Medical Physics.

9. A systematic review of methodologies, endpoints, and outcome measures in randomized trials of radiation therapy-induced nausea and vomiting. Dennis, K, et al. 2017, Support Care Cancer, pp. 20192033.

10. Development of the NIH Patient-Reported Outcomes Measurement Information System (PROMIS) gastrointestinal scale. Spiegel, BM, et al. 2014, The American Journal of Gastroenterology, pp. 18041814.

11. Methodology Series Module 2: Case-control Studies. Setia, MS. 2016, Indian journal of dermatology, pp. 146-151.

12. The American Joint Committee on Cancer: the 7th edition of the AJCC cancer staging manual and the future of TNM. Edge, SB and CC, Compton. 6, s.I. : Ann Surg Oncol, 2010, Vol. 17. doi: 10.1245/s10434010-0985-4. PMID: 20180029..

13. A Prospective Study of Nausea and Vomiting Following Breast Cancer Surgery. Wesmiller, SW, et al. 3, Pittsburgh : J Perianesth Nurs, 2017, Vol. 32. do: 10.1016/j/jopan.2015.12.009.

14. Fourth Consensus Guidelines for the Management of Postoperative Nausea and Vomiting. Gan, T, et al. 2, s.I. : Anesth Analg., 2020, Vol. 131. doi: 10.1213/ANE.0000000000004833.

15. Reduced incidence of postoperative nausea and vomiting in black South Africans and its utility for a modified risk scoring system. Rodseth, RN, et al. s.l. : Anesth Analg, 2010, Vol. 110.

16. Chemotherapy-induced nausea and vomiting in Asian women with breast cancer receiving anthracyclinebased adjuvant chemotherapy. Bordenau, L, et al. 4, s.I. : J Support Oncol, 2012, Vol. 10. doi: 10.1016/j.suponc.2011.10.007.

17. Triple-Negative Breast Cancer: A Comparison of Race and Survival. Doepker, MP, et al. s.l. : Am Surg, 2018, Vol. 84.

18. Post-mastectomy radiation therapy for triple negative, node-negative breast cancer. Haque, W, et al. s.I. : Radiation Oncol, 2019, Vol. 132.

19. Mechanisms of Chemotherapy Resistance in Triple-Negative Breast Cancer-How We Can Rise to the Challenge. Nedeljković, M and Damjanović, A. 9, s.I. : Cells, 2019, Vol. 8. https://doi.org/10.3390/cells8090957.

\section{Supplementary Files}

This is a list of supplementary files associated with this preprint. Click to download.

- RINV1.xIsx 